\title{
Non-small cell lung cancer and its treatment
}

\author{
Havvanur Akbulut ${ }^{1} \mathbb{D}$, Semanur İnceday1 $1^{1}$, Özüm Atasoy² \\ ${ }^{1}$ Biruni University School of Medicine, İstanbul, Turkey \\ ${ }^{2}$ Department of Radiation Oncology, Dr. Lütfi Kırdar Kartal Training and Research Hospital, Istanbul, Turkey
}

\begin{abstract}
Lung cancer is among the top causes of cancer-related deaths in Western countries. The two main types of lung cancer according to histological type include non-small cell lung cancer (NSCLC) (85\%) and small cell lung cancer (SCLC) (15\%). Many factors including smoking, air pollution, environmental factors, occupational carcinogens, diet, viral infections, history of lung diseases, genetic and immunological factors play a role in the etiology of lung cancer disease. Non-small cell lung cancer is frequently undiagnosed until late stages. Coughing is the most common symptom in $50-75 \%$ of patients, followed by hemoptysis, chest pain, and dyspnea. Other less common symptoms include laboratory abnormalities or paraneoplastic syndromes. Diagnosis requires biopsy for histological confirmation. Non-small cell lung cancer staging is important enough that it determines treatment options and prognosis. TNM staging is based on criteria of primary tumor characteristics ( $\mathrm{T}$ ), degree of lymph node involvement (N), and presence of metastasis (M). Non-small cell lung cancer treatment options are according to the cancer stage, however, certain aspects of the cancer itself, as well as other factors of the patient such as general health and respiratory function are also important. In this review, NSCLC etiology, diagnosis, treatment, and novel drugs used in treatment shall be discussed with context to the literature.

Keywords: Immunotherapy, new drugs, non-small cell lung cancer.
\end{abstract}

\section{NON-SMALL CELL LUNG CANCER}

Lung cancer is the top cause of cancerrelated death in western countries. Lung cancer is classified as non-small cell lung cancer (NSCLC) and small cell lung cancer (SCLC) according to histological type. Non-small cell lung cancer has many subtypes, in which the most common are adenocarcinoma, squamous cell carcinoma, and large cell carcinoma. ${ }^{[1,2]}$ Lung cancer staging hold great importance in determining prognosis. Evaluation of the primary tumor as well as the scope of thoracic and intrathoracic spread determines the resectability of the tumor. Non-small cell lung cancer grading uses TNM staging which is based on criteria of primary tumor characteristics $(\mathrm{T})$, degree of lymph node involvement $(\mathrm{N})$, and presence of metastasis $(\mathrm{M})$. The combination of $\mathrm{T}$, $\mathrm{N}$, and $\mathrm{M}$ is used to assign the tumor's final grade (I-IV). Treatment options vary according to tumor grade. ${ }^{[3]}$ Non-small cell lung cancer accounts for $80 \%$ of all lung cancers and five-year survival rate of these tumors range between 10-15\%. Apart from this, the literature has identified over 150 different prognostic factors that affect survival in NSCLC cases. The patient's performance status and weight loss are also prognostic factors of secondary degree of importance. ${ }^{[4]}$

\section{EPIDEMIOLOGY}

Incidence and mortality rates of lung cancer is highest in developed countries. In contrast, most less-developed geographical regions including Central/South America and Africa are estimated to have lower rates of lung cancer, although a majority of these countries do not have available reporting systems and most lung cancer cases are not reported, which is thought to prevent accurate evaluation of actual incidence. ${ }^{[5]}$

Primary lung cancer is the most prevalent form of cancer in our country. In all cancer-related deaths, lung cancer is the most common cause

Correspondence: Havvanur Akbulut. Biruni Üniversitesi Tıp Fakültesi, 34010 Topkapı, İstanbul, Türkiye.

e-mail: havvanurakbulut12@gmail.com 
of mortality for both genders and is known to be responsible for $12.8 \%$ of all cancer cases and $17.8 \%$ of all cancer-related deaths. In our country, according to the data from the Ministry of Health, lung cancer is most prevalent in the western and southern regions (Mediterranean, Aegean, and Central Anatolia 39.5/100,000) and least common in the southeastern and eastern regions $(17.7 / 100,000$ and 11.7/100,000). Nowadays, the incidence of lung cancer is one million new cases annually worldwide. This value accounts for $12.8 \%$ of all new cancer cases and increases by $3 \%$ ever year. Although the disease is preventable, it seems that the lung cancer epidemic will be unavoidable in our country, as well as worldwide. ${ }^{[6]}$

On a global scale, the number of lung cancer deaths is estimated to increase to 3 million by 2035. It is thought that the figures will be doubled in both men and women and that the twofold difference between genders will continue. The fastest increase is expected in the African region (AFRO) and Eastern Mediterranean (EMRO). The increase in the number of absolute lung cancer deaths in the more developed countries is mainly due to the aging of the population and the effect of the predominantly developing tobacco epidemic in less developed countries. ${ }^{[7]}$

\section{ETIOLOGY}

A large number of factors play a role in the etiology of lung cancer. Top factors including smoking, environmental factors such as air pollution, occupational carcinogens, diet, viral infections, previous lung diseases, and genetic and immunological factors. ${ }^{[8,9]}$

\section{Smoking}

Smoking is the most important factor in the development of lung cancer. Smoking is responsible for lung cancer in $85-94 \%$ of patients. Cancer development risk is 24-36 times more likely to develop in smokers compared to nonsmokers. Passive smoking leads to $3.5 \%$ increased risk. ${ }^{[8]}$ Smoking is associated with $70 \%$ of mortality rates in men and slightly lower rates in women. ${ }^{[10]}$

\section{Other forms of smoking}

Other forms of nicotine use including cigars and pipes have also been associated with increased lung cancer risk. However, this risk has been found to be lower compared to cigarettes. Smoking an average of five cigars a day is equivalent to smoking one packet of cigarettes. A prospective study on over 130,000 men conducted over a period of 12 years showed that cigar-smokers had 5.1 times relatively increased risk compared to non-smokers. People that smoked five or more cigars daily are at greater risk for lung cancer compared to people who have never smoked or people who smoke cigarettes. ${ }^{[11]}$

The impact of smoke from recreational drugs such as marijuana and cocaine has been less researched compared to tobacco smoke. Metaplastic histological and molecular changes have been described in cannabis or cocaine smokers in bronchial epithelium, similar to premalignant changes in conventional smokers. ${ }^{[12]}$

\section{Genetic factors}

Lung cancer is one of the most common genetic diseases and its molecular pathogenesis is substantially complex and heterogenous. Lung cancer is associated with various genetic and epigenetic changes (e.g. point mutation, amplification, insertion, deletion, and transposition), and is strongly associated with the activation of the pathway that induces inhibition of growth and tumor suppressor pathways. ${ }^{[13]}$ Mutational activation of oncogenes, inactivation of tumor suppressor genes, and changes in genes that play a role in the regulation of the cell cycle and DNA repair are the main molecular changes that occur in lung cancer. ${ }^{[14]}$

Genetic and epigenetic changes are common in NSCLC. The most commonly affected genes include epidermal growth factor receptor (EGFR), anaplastic lymphoma kinase (ALK), Kirsten rat sarcoma virus viral oncogene homologue (KRAS), ROS1, RET, MET, Echinoderm microtubuleassociated protein-like 4 (EML4), fibroblast growth factor receptor 1 (FGFR1), PTEN and PI3K genes. ${ }^{[15]}$

\section{Mutations}

The p53 gene has been shown to be a tumor suppressor gene with mutations commonly found in human cancers. Examination of 51 early-stage primary, resected NSCLC cancer samples using RNase protection assay and cDNA microarray, somatic mutations of p53 were concluded to play a significant role in the pathogenesis of early stage NSCLC. ${ }^{[16]}$ MicroRNAs (miRNA) are a 
small noncoding class of RNAs that regulate gene expression and play a role in the pathogenesis of human diseases including malignancies. MiR-21, a small, noncoding miRNA that is widely overexpressed in a wide variety of malignancies, may affect tumor progression by targeting tumor suppressor genes. The role of MiR-21 in NSCLC has been established and its regulation of PTEN has been clarified. MiR-21 regulates posttranscriptionally downstream suppressor PTEN expression and stimulates growth and invasion in NSCLC. This may be a potential therapeutic target for NSCLC. ${ }^{[17]}$

Epidermal growth factor receptor mutation is detected in about $20 \%$ of lung adenocarcinomas. Kirsten rat sarcoma virus viral oncogene homologue mutation is one of the most common oncogenic changes (20-30\%). KRAS mutation can be detected with PCR or sequencing methods. Kirsten rat sarcoma virus viral oncogene homologue mutation is generally found in smokers and tumors with KRAS mutations usually do not contain other oncogenic changes such as in EGFR or ALK. KRAS undergoes mutation in about $30 \%$ of adenocarcinomas, however, this activation is rare in other NSCLC types. C-myc amplification is found in about 50\% of all forms of NSCLC and overexpression in about 10\%. The c-myb protooncogene encodes a $75 \mathrm{kDa}$ nuclear transcriptional regulator protein. DNA hybridization studies have shown that three out of every four adenocarcinomas lose heterozygosity for c-myb. ${ }^{[18]}$ Some NSCLC analyses have shown errors in RNA transcription. It was found that $\mathrm{c}$-myb transcripts were not present in eleven NSCLC cell-lines. These results may reveal that abnormal c-myb expression plays a role in the development of lung cancer.

C-erbB-2: The c-erbB-2 (neu) gene encodes a transmembrane, tyrosine-specific protein kinase, p18neU. The epidermal growth factor receptor is a putative growth factor receptor related to sequence and structure. The gene is frequently amplified in adenocarcinomas and mRNA, and protein levels are often elevated in tumors compared to normal tissue. ${ }^{[19]}$

Fibroblast growth factor receptor-1: The FGFR tyrosine kinase family consists of four kinases: FGFR-1, FGFR-2, FGFR-3, and FGFR-4. These act as cell surface receptors for fibroblast growth factors and play a critical role in embryonic development, cell proliferation, differentiation, and migration control. This FGFR tyrosine kinase family also has an important role in tumor pathogenesis and can be regulated by amplification, point mutation, or translocation. The FGFR1 gene on chromosome 8 is one of the most common genes proliferating in human cancers. The results of several studies show that FGFR1, FGF2 and FGF9 ligands have a combined expression in human lung cancers.

MET: MET amplification occurs in 5-10\% of NSCLC. High gene copy numbers are more common in squamous cell carcinomas compared to adenocarcinoma. Excessive MET protein expression has been shown to be associated with poor prognosis.

ALK: The ALK protein was first discovered in 1997 as a chimeric protein resulting from $\mathrm{t}(2 ; 5)$ (p23; q35) chromosome translocation in anaplastic large cell lymphoma. In 2007, another ALK translocation was found in NSCLC. A portion of ALK on chromosome 2 was inverted and fused to a part of the EML 4 gene (Echinoderm microtubule associated protein-like 4 genes). This new ALK fusion protein can be activated in the cytoplasm without requiring a ligand to activate the RAS/RAF/MEK, PI3K/AKT/mTOR and JAK/STAT signaling pathways. ALK EML 4 fusion occurs in $4-7 \%$ of NSCLC, and is usually prevalent among younger, non-smoking, and clinically advanced patients.

ROS- 1 is a protooncogene on chromosome 6 that encodes the transmembrane tyrosine kinase receptors of the insulin receptor family. The protein kinase domain is similar to ALK. ROS-1 translocation is observed in 1-2\% of adenocarcinoma patients. In lung adenocarcinomas, the ROS-1 gene may be fused with several different genes, but the most common is the CD74-ROS-1 fusion. ROS-1 fusion is more common among younger patients, women, and nonsmokers.

RET: RET is a protooncogene that encodes a receptor tyrosine kinase involved in neural crest formation. Fusion of the RET gene with six different genes has been identified in approximately 1-2\% of adenocarcinomas.

DDR2 is a membrane-bound tyrosine kinase receptor that binds collagen, a major component 
of the extracellular matrix in the lungs. DDR2 mutations occur in 3-4\% of squamous cell carcinomas. It is estimated that DDR2 may be a potential new target in the treatment of lung squamous cell carcinoma.

PI3K protein families are lipid kinases located in the PI3K/AKT/A1 pathway. PIK3CA mutations are found in approximately 1-3\% of NSCLC cases. They are usually associated with other oncogenic mutations, especially EGFR, KRAS, and ALK.

TP53 is found on the short arm of chromosome 17. This tumor suppressor gene is involved in the control of cell cycle, DNA repair, and apoptosis. Mutations of the TP53 gene are among the most common genetic changes that occur in human cancers, and about $80 \%$ of TP53 gene mutations are faulty mutations. TP53 inactivation occurs in $90 \%$ of small cell carcinomas and in approximately $65 \%$ of NSCLC.

LKB-1: Biallelic inactivation of LKB-1 is the third most common genetic disorder in NSCLC after TP53 and KRAS and is found in 30\% of primary tumors. Inactivating mutations are more common in adenocarcinomas than in squamous cell cancers; it is also more common among males, smokers, and in poorly differentiated adenocarcinomas.

PTEN is a tumor suppressor gene localized on chromosome 10 that encodes lipid and protein phosphatase which inhibits the PI3K/AKT/mTOR signaling pathway. PTEN mutations occur in about $5 \%$ of NSCLC. It is more common in squamous cell carcinomas compared to adenocarcinoma. Decreased PTEN expression levels occur in about $75 \%$ of NSCLC cases.

In lung adenocarcinoma, global hypomethylation can be seen in advanced stages. In NSCLC, hypomethylation can reportedly activate inactive oncogenes and cause genomic imbalance leading to cancer.

Histone deacetylases catalyze the removal of acetyl groups in the histone tail, subsequently leading to a transcriptionally inactive heterochromatic state. Overexpression of histone deacetylases (HDAC) has been observed in lung cancers. ${ }^{[13]}$

\section{Sex}

Lung cancer passed breast cancer as the top cause of cancer-related deaths in women since the late 1980s and is currently responsible for two times more deaths compared to breast cancer. ${ }^{[20]}$

Smoking prevalence is higher in men (23.1\%) than women (18.3\%); however, this difference is narrowing. ${ }^{[21]}$ There has been a $2.5 \%$ decrease in lung cancer deaths in men and a 0.9\% decrease in lung cancer deaths in women. Although the overall incidence of corrected lung cancer is higher in males than in females, this difference is reduced due to the reduced incidence of lung cancer in males. Smoking continues to be the most important factor in lung cancer development in women. Some studies report that $80 \%$ of cases are associated with smoking in women. ${ }^{[22]}$

Genes in females may render them more vulnerable to the harmful effects of smoking. Hormones in women such as estrogen may be directly or indirectly involved with cancer progression. Some treatments may have better outcomes in women than in men. Survival risk is better adjusted in both treated and non-treated elderly women with early lung cancer compared to men. Despite the fact that men are at greater risk of developing lung cancer and morbidity, most are still unaware of signs and symptoms that they should present. This is partially due to generally low understanding of health and the fact that men are less likely to research information regarding health compared to women. ${ }^{[23]}$

\section{Race and ethnic background}

Race is a complex factor with a generally strong socioeconomic relationship. However, racial differences in diseases may shed light on specific matters regarding a certain subpopulation. ${ }^{[11]}$ Menck and Henderson ${ }^{[24]}$ reported that incidence of lung cancer was significantly higher in Blacks and native Hawaiians compared to other Polynesians, and lower in Japanese Americans and Hispanics compared to Caucasians in the USA.

\section{Age}

Mean population age in most populations of developing countries are rising, and cancer is a disease of the elderly. While smoking prevalence is $9.3 \%$ in people ages 65 and older, $21.4 \%$ in ages $18-24,23.7 \%$ between $25-44$ years, and $22.6 \%$ between ages $45-64,65 \%$ of lung cancer patients are over age $65 .{ }^{[25,26]}$ Mean age at diagnosis is 
over age 70. This difference between low smoking prevalence and high cancer rate among the elderly population reflects likely history of smoking in the elderly population. In the last decade, incidence and mortality of lung cancer has decreased in people aged 50 and younger, but has increased in people aged 70 and older. ${ }^{[27]}$ Very few studies have investigated lung cancer and its treatment in the elderly population. The latest studies have concluded that elderly patients with lung cancer may particularly benefit from surgical treatment in early diagnosis, and single-agent chemotherapy in late term diagnosis. Younger patients may benefit from many different treatments. ${ }^{[28,29]}$

\section{Diet and obesity}

Diet is reportedly associated with about 30\% of all cancers. Many reports have demonstrated that dietary factors contribute to lung cancer risk. For example, low concentrations of serum antioxidants such as vitamins $\mathrm{A}, \mathrm{C}$, and $\mathrm{E}$ has been associated with lung cancer. Vitamin A can be obtained from animal (retinol) and vegetable (carotenoid) sources; the vegetable components have been shown to have protective effects only against lung cancer. In particular, $\beta$-carotene, a prominent carotenoid, has been shown to have the greatest protective effects against lung cancer. Protective effects of vitamin $\mathrm{C}$ and $\mathrm{E}$ ( $\alpha$-tocopherol) has also been shown. ${ }^{[1]}$

\section{Other lung diseases and airway obstructions}

Some non-malignant diseases have been associated with increased risk, especially of COPD and lung cancer. Smoking is the main cause of both lung cancer and COPD. One study on women with lung cancer who had never smoked found a statistically significant relationship between airflow obstruction and development of lung cancer. ${ }^{[11]}$

\section{Infections}

While infections have been considered a causal factor in lung cancer, this is controversial. For example, oncogenic viruses were proposed as a cause of lung cancer. Early studies on pulmonary adenomatosis in sheep caused by Jaagsiekte sheep retrovirus showed pathologic resemblance to human bronchioalveolar carcinoma; however, there is insufficient evidence to prove that there is an association between the two diseases and that viruses contribute to development of human bronchioalveolar carcinoma. ${ }^{[30]}$

Epstein-Barr virus related to Burkitt's lymphoma and nasopharynx carcinoma was associated with a rare form of lung cancer, lymphoepithelioma-like carcinoma, in Asian patients; however, this association was not found in Western populations. ${ }^{[31]}$

Recently, DNA from a new virus, the Torque teno virus, has been detected at high levels in lung cancer patients with idiopathic pulmonary fibrosis, and although this may suggest association with Torque teno virus infection, more research is needed to clarify the development of lung cancer in idiopathic pulmonary fibrosis and to determine its clinical significance. ${ }^{[32]}$

\section{CLASSIFICATION OF LUNG CANCER}

There are two main types of lung cancer, including NSCLC (85\%) and SCLC (15\%). The WHO classifies NSCLC into three main types: adenocarcinoma, squamous cell carcinoma, and large cell carcinoma. Adenocarcinomas are the most commonly seen NSCLC type and account for $40 \%$ of all lung cancers. ${ }^{[33]}$

Unlike other lung cancers, adenocarcinomas are poorly associated with smoking and are often seen in non-smoking female patients. They can develop from previous parenchymal scar tissue and are therefore also referred to as "scar carcinoma". They are frequently located in peripheral and subpleural areas. They may appear as radiologically well-circumscribed lobulated or speculated contoured lesions or solitary pulmonary nodules. Air bronchograms may appear on computed tomography (CT). Peripheral localized masses show circular growth along the pleura by direct pleural invasion. ${ }^{[34]}$

Squamous cell carcinoma accounts for 25-30\% of lung cancers; they tend to emerge from cells in the airway epithelium. ${ }^{[5]}$ This lung cancer type is closely related to smoking and generally shows central localization and cavitation. When the mass is centrally located, it typically causes total or subtotal obstruction, resulting in postobstructive pneumonia or atelectasis. ${ }^{[34]}$

Large cell carcinoma is the least common form of lung cancer. They account for about $5-10 \%$ of all lung cancers. They are closely 
related to smoking and are rapidly growing, early metastasizing cancers with poor prognosis. They are generally peripherally localized but may also show central localization. The radiological appearance is typically in the form of large peripheral masses. ${ }^{[35]}$

\section{DIAGNOSIS}

Non-small cell lung cancer is frequently undiagnosed until late stages of the diseases. Coughing is the most common symptom in $50-75 \%$ of patients, followed by hemoptysis, chest pain, and dyspnea. ${ }^{[36,37]}$ Other common symptoms include laboratory abnormalities and paraneoplastic symptoms. Diagnosis requires histological confirmation with biopsy.

Lung cancer patients are divided in four groups according to signs and symptoms. ${ }^{[38,39]}$

1. Signs and symptoms associated with primary tumor: Coughing, shortness of breath, and hemoptysis are the most common symptoms. The tumor may also cause airway obstruction leading to stridor, localized rhonchus, atelectasis, pneumonia, and abscess. ${ }^{[38,39]}$

2. Signs and symptoms associated with intrathoracic spread: Intrathoracic invasion of lung cancer may occur via direct extension or lymphatic spread. This spread may involve nerves, the chest wall and pleura, vascular structures, and intrathoracic organs. Nerve involvement may lead to hoarseness, diaphragmatic paralysis, Horner's syndrome, arm weakness, atrophy of the hand muscles, chest wall and pleural involvement, chest pain, pleurisy and shortness of breath due to involvement of vascular structures, superior vena cava syndrome, cardiac tamponade and esophageal involvement. ${ }^{[38-40]}$

3. Signs, symptoms, and laboratory tests associated with extrathoracic metastasis: About one-third of lung cancer patients have signs and symptoms associated with extrathoracic involvement. Distant metastases are common in bones, the liver, brain, suprarenal glands, skin, and lymph nodes. ${ }^{[17]}$ Localized bone pain and elevated serum calcium and alkaline phosphatase are indicative of bone metastasis. There are no specific symptoms regarding the suprarenal glands. Elevated serum transaminase 7 levels, tenderness and pain in the epigastric region, and loss of appetite suggest liver metastasis. Brain metastasis is found in $10 \%$ of patients at admission. Headache, nausea and vomiting, personality changes, focal neurological findings, balance defect, confusion are the signs and symptoms detected in patients with brain metastasis. Other findings such as weight loss and anemia may also suggest distant metastasis. ${ }^{[38,39]}$

4. Paraneoplastic syndromes: These signs are seen in more than $10 \%$ of lung cancer patients. Paraneoplastic syndromes include signs and symptoms that may not be directly associated with the metastatic or primary tumor. Paraneoplastic syndromes associated with lung cancer may be grouped as endocrine (hypercalcemia, inappropriate $\mathrm{ADH}$ release, Cushing syndrome, etc.), neurological (LambertEaton syndrome, encephalomyelitis, neuropathy, etc.), metabolic (hypouricemia, hyperamylasemia, etc.), renal (glomerulonephritis, nephrotic syndrome), hematologic (thrombocytosis, leukocytosis, eosinophilia, etc.), skeletal (hypertrophic osteoarthropathy, clubbing), collagen-vascular (dermatomyositis, vasculitis, SLE, polymyositis), skin (Sweet Syndrome, Bazex Syndrome, hypertrichosis, erythroderma etc.), coagulopathy (DIC, thrombophlebitis, etc.) and other (fever, cachexia, etc.). ${ }^{[38-40]}$

Diagnosis also requires TNM staging as a guide for cancer treatment options.

\section{Radiological imaging in lung cancer}

The main purpose of radiological imaging is diagnosis of the tumor and evaluation of operability. The first radiological method to be selected is two-way chest radiography. Lateral $\mathrm{X}$-ray adds a third dimension, or depth, to posteroanterior chest X-ray. ${ }^{[41]}$ Radiographic findings for lung cancer are classified as direct and indirect findings. Direct findings include 
mass, nodule, or infiltrative lesions. Lesions with ground glass opacity are frequently observed in early stage bronchioalveolar carcinomas. Indirect findings include nonresponsive pneumonia or atelectasis, unilateral air trapping, pleural effusion, and diaphragmatic palsy. Round or oval densities up to $3 \mathrm{~cm}$ in diameter in the lung are referred to as nodules while those larger than $3 \mathrm{~cm}$ are called masses. ${ }^{[42]}$

\section{Positron emission tomography}

Positron emission tomography (PET) is a noninvasive method based on imaging of in vivo biological, physiological, and pathological processes. With this method, images are obtained using radionuclides such as the "Cyclotron" fluoride product Fluoride-18 (F-18), Carbon-11 (C-11), Oxygen-15 (O-15) and Nitrogen-13 (N-13). PET is indicated for use in fields such as oncology, neuropsychiatry, and cardiology. One of the most extensively studied subjects in oncology is lung cancer, in which both tomographic imaging of the thorax and entire body can be performed if necessary. ${ }^{[43]}$

\section{Laboratory tests}

Complete blood count as well as biochemical tests including alkaline phosphatase, albumin, ALT, AST, GGT, total bilirubin, urea, creatinine, $\mathrm{LDH}, \mathrm{Na}, \mathrm{K}, \mathrm{Ca}$ and electrocardiography should be performed in all patients. Other tests do not require routine evaluation. ${ }^{[4]} \mathrm{A}$ wide variety of molecular and biological substances (such as CEA, sialic acid, $\beta$-HCG, neuron-specific enolase, and pro-GRP) have been investigated in clinical trials to demonstrate the presence, staging, or progression of lung cancer. Currently, a specific and sensitive tumor marker that can detect lung cancer at an early stage or affect the follow-up of the disease has not yet been established or recommended for routine use. ${ }^{[44-46]}$

Interventional methods for Lung cancer diagnosis:

1. Bronchoscopy: Nowadays, bronchoscopy is used in the diagnosis and staging of lung cancer and in some treatment applications (brachytherapy, laser treatment, endobronchial stent application, etc.). It is currently the main method for acquiring tissue diagnosis of endoscopic lung cancers, however, its efficiency is limited to the location and size of the tumor. An endobronchial tumor may be an exophytic mass lesion that partially or completely obstructs the bronchial lumen, but may also be submucosal or peribronchial disease. Endoscopic findings may not always be detected in peripheral lung carcinomas. ${ }^{[47]}$

2. Transthoracic needle aspiration: Percutaneous transthoracic needle aspiration, which is performed with the guidance of fluoroscopy, ultrasound, and $\mathrm{CT}$, is an effective and reliable method for diagnosing thoracic malignancies. Its rate of diagnosis is between $80-95 \%$, especially for tumors smaller than $3 \mathrm{~cm}$ diameter. Computed tomography-guided interventions have specificity of 96-100\%, and sensitivity of $89-92 \%$. Rate of false positivity or inadequate diagnosis ranges between 10-30\%. Repeated interventions have diagnosis rate of $35-65 \% .{ }^{[44]}$ Factors that effect diagnostic value include the localization, diameter, structure, specialist pathologist supervision, and needle gauge. Computed tomography-guided transthoracic needle aspiration is preferred in the following situations: lesions that cannot be localized with fluoroscopy and ultrasound, hilar and mediastinal masses, thoracic inlet lesions, cases with superior vena cava syndrome, oblique and angled procedures, and generalized bullous diseases. ${ }^{[48,49]}$ Indications for transthoracic needle aspirations include solitary and multiple pulmonary nodules, consolidation, cavitation, and abscess presence. The indications for transthoracic needle aspiration are: solitary and multiple pulmonary nodules, consolidation, and presence of cavitation and abscess. Bleeding diathesis, severe pulmonary hypertension, suspected hydatid cyst, vascular lesions, diffuse emphysema, presence of uncontrollable coughing, noncooperative patient, and pneumonectomy are the among the main contraindications. ${ }^{[50]}$ The most common complication of transthoracic needle aspiration is pneumothorax (25-42\%) which requires tube thoracostomy in 5-12\% of cases. Other complications include self-limiting intraparenchymal hemorrhage, 
severe hemorrhage, air embolism, and tumor implantation at the site of the needle. ${ }^{[44,49-52]}$

3. Evaluation of pleural fluid: Lung cancer is accompanied by pleural fluid in 50\% of cases. ${ }^{[51,53]}$ Pleural fluid is detected in $8-15 \%$ of lung cancer patients. A portion of pleural fluid is caused by paramalignant causes (postobstructive atelectasis, pneumonia, and mediastinal lymphatic obstruction). Thoracentesis is the most available method for obtaining pleural fluid when there is suspicion of malignancy. Its diagnostic value is considered between 50-60\%. Detection of malignant cells in cytological evaluation of 50-100 cc pleural fluid is sufficient in $65 \%$ of cases. Cytological diagnosis depends on the type of tumor. The best results are obtained in adenocarcinoma, with poorer results in small cell lung carcinoma, lymphoma, and mesothelioma. Thoracentesis should be repeated since repeated thoracentesis may prove involvement in 30\% of patients due to new cell exfoliation, and if diagnosis cannot be made, closed pleural biopsy and thoracoscopy are the next step. Complications of thoracentesis are pneumothorax, reexpansion pulmonary edema and rarely air embolism. ${ }^{\text {[38] }}$

\section{STAGING}

Non-small cell lung cancer staging is as vital that it determines treatment options and prognosis. TNM staging is based on criteria of primary tumor characteristics $(\mathrm{T})$, degree of lymph node involvement $(\mathrm{N})$, and presence of metastasis $(\mathrm{M})$. The combination of $\mathrm{T}, \mathrm{N}$, and $\mathrm{M}$ categories are used to evaluate the general stage (I-IV) of the tumor. Treatment options change according to cancer stage. ${ }^{[3]}$

$T$ factor evaluation: The $\mathrm{T}$ factor defines the characteristics of the primary tumor. An evaluation is made based on factors such as the tumor's size, vicinity, invasion features, and related nodules. ${ }^{[54,55]}$ Tx refers to when the primary tumor cannot be detected in imaging or bronchoscopy despite malignant cells in sputum or bronchoscopic fluids are classified as Tx; no evidence of tumor is classified as T0, and carcinoma in situ tumor is evaluated as Tis. In measuring the tumor size, the long diameter in the axial sections of the thoracic CT taken in the inspiration is taken into consideration. Tumors up to $5 \mathrm{~cm}$ in diameter are defined as T1a, T1b, T1c, T2a, T2b, tumors with diameter between 5-7 cm are considered T3, and tumors $>7 \mathrm{~cm}$ are considered T4 (Table 1). ${ }^{[3,56]}$

Tumor Invasion: According to the new staging system, tumors in the main bronchus are considered T2, regardless of distance from the carina. Similarly, atelectasis or partial and total obstructive pneumonia are in the same group and evaluated as T2. Visceral pleura invasion is also classified as T2. Chest wall invasion, including superior sulcus tumors, parietal pleura, parietal pericardium, phrenic nerve invasion, or satellite nodule(s) in the same lobe are classified as T3. In the new staging, mediastinal invasion was excluded from $\mathrm{T}$ evaluation. Diaphragmatic invasion was T4 in the $8^{\text {th }}$ edition. Heart, large vessels, trachea, recurrent laryngeal nerve, esophagus, vertebral corpus, carina invasions and nodule-nodules in different lobes of the same side lung are also included in T4 (Table 1). ${ }^{[3,56]}$

$N$ factor evaluation: There was no changes to the $\mathrm{N}$ factor in the eighth edition TNM staging. In the seventh edition staging, the evaluation was made in this respect when staging eighth TNM, especially since the N2 lymph node did not take multiple-station or extracapsular invasion features into consideration. Analyzes showed that single-station $\mathrm{N} 2$ disease had a relatively better prognosis than multi-station N2 disease, and similarly, single station N2 (skip metastasis) without hilar lymph nodes had a better prognosis than N2 disease with hilar lymph node, but due to insufficient number of patients they were not taken into consideration in the new staging. Therefore, the lymph node classification in the seventh edition TNM staging was replaced in the eighth TNMs (Table 1). ${ }^{[54,56,57]}$

$M$ factor evaluation: Seventh edition TNM staging considers extrathoracic distant organ metastases as M1b. However, according to eighth edition TNM staging, patients with single metastasis in a single distant organ have better prognosis compared to patients with multiple metastases in single or multiple distant organs, which has been taken into consideration in 
Table 1. Definitions for TNM descriptor (American Joint Commission on Cancer (AJCC) $8^{\text {th }}$ edition) ${ }^{[56]}$

\begin{tabular}{ll}
\hline & \multicolumn{1}{c}{ T (primary tumor) } \\
\hline T0 & No primary tumor \\
Tis & Carcinoma in situ (squamous or adenocarcinoma) \\
\hline T1 & Tumor $\leq 3 \mathrm{~cm}$ \\
T1mi & Minimally invasive adenocarcinoma \\
T1a & Superficial spreading tumor in central airways ${ }^{*}$ \\
T1a & Tumor $\leq 1 \mathrm{~cm}$ \\
T1b & Tumor $>1$ but $\leq 2 \mathrm{~cm}$ \\
T1c & Tumor $>2$ but $\leq 3 \mathrm{~cm}$ \\
\hline T2 & Tumor $>3$ but $\leq 5 \mathrm{~cm}$ or tumor involving: visceral pleura, $\nmid$ main bronchus (not carina), atelectasis to hilum $\dagger$ \\
T2a & Tumor $>3$ but $\leq 4 \mathrm{~cm}$ \\
T2b & Tumor $>4$ but $\leq 5 \mathrm{~cm}$ \\
\hline T3 & Tumor $>5$ but $\leq 7 \mathrm{~cm}$ or invading chest wall, pericardium, phrenic nerve; or separate tumor nodule(s) in the same lobe \\
\hline T4 & Tumor $>7 \mathrm{~cm}$ or tumor invading: mediastinum, diaphragm, heart, great vessels, recurrent laryngeal nerve, carina, trachea, esophagus, \\
\hline & spine; or tumor nodule(s) in a different ipsilateral lobe \\
\hline N0 & No regional node metastasis \\
\hline N1 & Metastasis in ipsilateral pulmonary or hilar nodes \\
\hline N2 & Metastasis in ipsilateral mediastinal or subcarinal nodes \\
\hline N3 & Metastasis in contralateral mediastinal, hilar, or supraclavicular nodes \\
\hline & \\
\hline M0 & No distant metastasis \\
\hline M1a & Malignant pleural or pericardial effusion + or pleural or pericardial nodules or separate tumor nodule(s) in a contralateral lobe \\
\hline M1b & Multiple extrathoracic metastases (1 or $>1$ organ) \\
\hline Mle & \\
\hline
\end{tabular}

the new staging. This change has aimed to better define treatment and foresee prognosis in oligometastatic disease. The new staging system considers lack of distant organ metastasis as M0; metastatic nodule(s) in the opposite lung, pleural or pericardial metastatic nodules, or malignant pleural or pericardial effusion as M1a; single metastasis in a single extrathoracic organ as M1b; and multiple extrathoracic metastases in single/ multiple organs as M1c (Table 1). ${ }^{[56]}$

Computed tomography is the only useful criterion in evaluating malignancy. Nodules with short diameter of over $1 \mathrm{~cm}$ in CT are considered abnormal. Primary staging of mediastinal lymph nodes in CT have positive and negative predictive value of $56 \%$ and $83 \%$, respectively. ${ }^{[58]}$

Fluorodeoxyglucose positron emission tomography (FDG-PET) is more suitable for staging mediastinal nodes as it not only evaluates size but is also based on metabolic activity. The combination of FDG-PET and CT is better than CT or PET alone, with a high accuracy of $90 \%$, and should be used in the staging of NSCLC when possible. Only negative $\mathrm{CT}$ and negative FDG-PET or PET-CT prevent the need for preoperative mediastinoscopy or minimally invasive techniques. ${ }^{[3]}$

\section{TREATMENT}

\section{Current treatment methods}

Surgery: Patients with stage I, II and IIIA NSCLC generally undergo operation to remove the tumor if the tumor is found resectable and the patient can tolerate the surgery. Surgeons

Table 2. Lung cancer stage grouping (AJCC $8^{\text {th }}$ edition) ${ }^{[56]}$

\begin{tabular}{|l|c||c|c|c|c|}
\hline T/M & Subcategory & N0 & N1 & N2 & N3 \\
\hline \hline \multirow{2}{*}{ 1 } & T1a & IA1 & IIB & IIIA & IIIB \\
\cline { 2 - 6 } & T1b & IA2 & IIB & IIIA & IIIB \\
\cline { 2 - 6 } & T1c & IA3 & IIB & IIIA & IIIB \\
\hline \multirow{2}{*}{ T2 } & T2a & IB & IIB & IIIA & IIIB \\
\cline { 2 - 6 } & T2b & IIA & IIB & IIIA & IIIB \\
\hline T3 & T3 & IIB & IIIA & IIIB & IIIC \\
\hline T4 & T4 & IIIA & IIIA & IIIB & IIIC \\
\hline M1 & M1a & IVA & IVA & IVA & IVA \\
\cline { 2 - 6 } & M1b & IVA & IVA & IVA & IVA \\
\cline { 2 - 6 } & M1c & IVB & IVB & IVB & IVB \\
\hline
\end{tabular}


can remove a lobe or portion of the lung that contains the tumor. To determine whether or not the tumor is resectable, imaging studies and biopsies are performed, as well as an assessment of patient factors to determine operability. Many surgeons use video-assisted thoracoscopic surgery (VATS), in which a small incision is made in the chest and a thoracoscope is placed. Through this small incision, a lobe can be removed through the scope without requiring a larger incision. ${ }^{[59]}$

Chemotherapy: About $40 \%$ of newly diagnosed lung cancer patients are Stage IV. The treatment goal in these patients is to increase survival and reduce adverse events related to the disease. For stage IV NSCLC, cytotoxic combination chemotherapy is the first treatment that may be affected by histology, age versus comorbidity and performance status (PS). The American Society of Clinical Oncology states that the treatment of a patient with 0 or 1 PS is a regimen of platin (cisplatin or carboplatin) plus paclitaxel, gemcitabine, docetaxel, vinorelbine, irinotecan or pemetrexed. ${ }^{[50]}$ The results of four large multicenter randomized clinical trials examining the above agents with platin or carboplatin yielded similar results. The results of these studies showed that no regimen showed a significant advantage over any other combination. Evidence for patients with PS of two suggests that they typically need only one non-platinum drug. ${ }^{[60]}$ For chemotherapy treatment, serious adverse events should lead to changes in agents. Treatment should also discontinue of the cancer grows or the if disease is stable but the treatment does not shrink tumors after four treatment cycles. Patients with PS of 3 typically do not benefit from cytotoxic chemotherapy because the risk of adverse events can significantly worsen their quality of life. Basic supportive care is generally recommended for these patients. ${ }^{[61]}$

Adjuvant treatment: Some patients who undergo resection surgery may benefit from adjuvant treatment to reduce the risk of relapses. Adjuvant treatment includes radiotherapy, chemotherapy, and target-specific treatment. Stage IIA, IIB, and IIIA NSCLC patients generally receive chemotherapy after surgery to prolong life expectancy and destroy any remaining cancer cells. ${ }^{[62]}$
Radiotherapy: Radiotherapy (RT) uses highenergy rays to damage the DNA inside cancer cells and destroy them. ${ }^{[63]}$ RT has a potential role in all stages of NSCLC, as either definitive or palliative therapy. Radiation oncology input as part of a multidisciplinary evaluation or discussion should be provided for all patients with stage III NSCLC, with early-stage disease who are medically inoperable, who refuse surgery, or who are high-risk surgical candidates, and with stage IV disease that may benefit from local therapy. ${ }^{[64]}$

Treatment should be planned according to stage of disease and performance status.

\section{TREATMENT APPROACH ACCORDING TO STAGING}

Treatment of TXNOMO and superficial tumors: As this is a high-risk group, spiral thoracic CT scan is recommended in patients who have normal chest radiography and physical examination but positive sputum cytology. Surgical treatment is recommended if a lesion is detected on spiral thoracic CT. Autofluorescent bronchoscopy should be performed when the lesion cannot be detected in spiral thoracic CT. In patients with superficial tumors with an invasion depth of $<3 \mathrm{~mm}$ and length $<1 \mathrm{~cm}$, the recommended treatment is surgery. Photodynamic therapy, brachytherapy, argon plasma coagulation, electrocauterization, and cryotherapy are the treatment options for patients who are not candidates for or do not accept surgery. Nd-YAG laser therapy is not recommended because high risk of perforation. Lesions that cannot be detected with spiral $\mathrm{CT}$ or autofluorescent bronchoscopy should be followed-up.

Treatment of Stage IA and IB tumors: The standard approach in the treatment of these tumors is surgical resection. Lobectomy and, if necessary, pneumonectomy are resections applied for this purpose. Methods such as wedge resection or segmentectomy may be conducted in patients with limited pulmonary functions. Additional postoperative treatment is not recommended in patients who have undergone complete resection. If complete resection has not been performed (surgical margin positivity), complementary surgical resection is conducted. 
When this cannot be conducted, radiotherapy is the preferred method. Stereotactic ablative radiotherapy (SABR, also known as SBRT) is recommended for patients who are medically inoperable or who refuse to have surgery after thoracic surgery evaluation. ${ }^{[64]}$ SABR has achieved good primary tumor control rates and overall survival, and higher than conventionally fractionated radiotherapy, although not proven equivalent to lobectomy. ${ }^{[65]}$ In patients treated with surgery, postoperative radiotherapy (PORT) is not recommended unless there are positive margins or upstaging to N2. ${ }^{[64]}$

Treatment of stage IIA and IIB tumors: Surgical resection is the choice of treatment in this stage. Routine lymph node dissection is recommended. Postoperative radiotherapy is not recommended when complete resection is performed in N1 cases. Adjuvant radiotherapy reportedly does not affect survival but reduces local recurrences. Postoperative chemotherapy should not be routinely administered in patients who have undergone complete resection. Surgical treatment should be preferred in T3NO cases.

Concurrent chemotherapy/RT is recommended for patients with inoperable stage II (node-positive) and stage III NSCLC. ${ }^{[6]}$ The most commonly prescribed doses for definitive RT are 60 to $70 \mathrm{~Gy}$ in $2 \mathrm{~Gy}$ fractions. Doses of at least $60 \mathrm{~Gy}$ should be given.Preoperative concurrent chemotherapy/RT is an option for patients with resectable stage IIIA (minimal N2 and treatable with lobectomy) NSCLC and is recommended for resectable superior sulcus tumors. ${ }^{[67]}$ Doses of 45 to $54 \mathrm{~Gy}$ in 1.8 to 2 Gy fractions are standard preoperative doses. Definitive RT doses delivered as preoperative chemoRT can safely be administered and achieve promising nodal clearance and survival rates, but require experience in thoracic surgical techniques to minimize the risk of surgical complications after high-dose RT. ${ }^{[68]}$

Treatment of IIIB tumors: Surgical resection may be performed in some selected T4N0 patients (such as satellite nodule or carina involvement). Chemotherapy is the treatment of choice for malignant pleural effusion. In patients with stage IIIB without malignant pleural effusion, sequential chemoradiotherapy is often used. The five-year survival rate in these stage patients is reported as $3-7 \%$.
Treatment of stage IV tumors: The standard treatment of stage IV cases is chemotherapy. In some cases, palliative radiotherapy may be

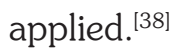

RT is recommended for local palliation or prevention of symptoms (such as pain, bleeding, or obstruction). Definitive local therapy to isolated or limited metastatic sites (oligometastases) (including but not limited to brain, lung, and adrenal gland) achieves prolonged survival in a small proportion of well-selected patients with good performance status who have also received radical therapy to the intrathoracic disease. ${ }^{[69]}$

\section{IMMUNOTHERAPY}

Lung cancer is the top cause of cancerrelated mortality. Despite aggressive treatment with surgery, radiotherapy, and chemotherapy, the need has arisen for development of new therapeutic strategies such as immunotherapy due to small chance of long-term survival. ${ }^{[70]}$

\section{Control points of the immune system}

To understand immunotherapy, it is important to comprehend the concept of immune system checkpoints, as they are the molecules targeted by lung cancer immunotherapies. Immune system checkpoints are normally located in the person's immune cells and prevent the immune system from attacking normal healthy cells. However, cancer is misleading, since one way to prevent against attack by the immune system is to make and express these checkpoint proteins. However, cancer immunotherapies attempt to block these checkpoints to mandate that the body recognizes the cancer as foreign and initiate an attack.

\section{Immunotherapy for lung cancer}

Programmed cell death protein-1 (PD-1) antibody: One major immune system checkpoint targeted by NSCLC immunotherapies is PD-1, a receptor normally found on $\mathrm{T}$ cells, which can also be produced and expressed by lung cancer cells. Normally, this immune checkpoint binds to the site of the lung tumor, therefore, the immune system avoids fighting cancer. However, with PD-1 blocking drugs, the immune system can respond to and attack cancer cells. There are currently two drugs with PD-1 antibodies (or PD-1 checkpoint inhibitors), which are FDA-approved 
to treat advanced NSCLC. Both of these drugs are administered as an infusion every two to three weeks. These two drugs are Opdivo (nivolumab) and Keytruda (pembrolizumab).

Overview of nivolumab: As a PD-1 antibody, nivolumab has been studied in a number of trials in individuals with advanced NSCLC. For example, in a stage III study published in the New England Medical Journal (2015), docetaxel and nivolumab treatments were administered to individuals during or after an advanced NSCLC platinum-containing chemotherapy regimen. The results showed that nivolumab groups lived longer than docetaxel groups. In addition to survival benefit, the study considered nivolumab was generally considered safer than docetaxel. Pneumonia is one of the major side effects of cancer treatment that causes concern. In this study, pneumonia rarely occurred in the nivolumab group and had mild severity when it did occur. However, other concerning side effects associated with nivolumab aside from pneumonia include skin problems (i.e. rash and itching), digestive problems (i.e. diarrhea), abnormal live enzyme blood tests, thyroid problems, and infusion-related reactions.

Overview of pembrolizumab: Pembrolizumab is FDA approved to treat advanced NSCLC in individuals with no specific genetic abnormality related to lung cancer (EGFR mutation or an ALK translocation) and in those in which at least half of the tumor cells are positive for PD-L1. PD-L1 is a protein that normally binds to PD-1 in $\mathrm{T}$ cells and prevents them from attacking cancer cells. Pembrolizumab was also approved for the treatment of non-advanced NSCLC, regardless of whether tumor cells were stained positive for PD-L1. In general, the most common side effects of pembrolizumab include diarrhea, fatigue, and fever. One study reported the pembrolizumab group had a higher rate of pneumonitis (5.8\% vs. $5.7 \%$ ) compared to the chemotherapy group.

\section{PD-L1 antibody}

Tecentriq (atezolizumab) is an FDA approved drug for the treatment of patients with advanced NSCLC whose disease continues to worsen during or after exposure to platinum-containing chemotherapy. Atezolizumab is slightly different from nivolumab or pembrolizumab since it is a
PD-L1 antibody. In other words, protein that normally bind to PD-1 (a receptor on $\mathrm{T}$ cells) specifically target PD-L1, preventing them from attacking cancer cells. Atezolizumab, like the other two drugs, is administered as an infusion. In a 2017 study published in The Lancet, patients who had previously received platinum-based chemotherapy for advanced NSCLC were randomized to receive atezolizumab or docetaxel. The atezolizumab group had less severe effects than the docetaxel group (43\% vs. $15 \%)$. However, the most common side effects in people taking atezolizumab include fatigue, nausea, decreased appetite, and weakness. Pneumonia occurred in $1.6 \%$ of patients in the atesolizumab group, with low and severe pneumonia (grade 3 or 4 ) in less than $1 \%$.

Durvalumab (Imfinzi) is another FDA approved immunotherapy which targets the PD-L1 protein. However, this treatment is used in patients whose cancer has not worsened after chemotherapy and radiotherapy, and more specifically in patients with stage III NSCLC whose tumors cannot be surgically removed. Common side effects of durvalumab in stage III NSCLC patients include cough, fatigue, upper respiratory tract infections, difficulty breathing, and rash. Serious risks include immune-mediated side effects such as pneumonia, hepatitis, and colitis.

\section{Future immunotherapies}

An immunotherapy called Yervoy (ipilimumab) has been found to prolong survival in patients with metastatic melanoma. This drug targets cytotoxic T-lymphocyte antigen 4 (CTLA-4), the primary regulator of $\mathrm{T}$ cell function in the immune system. Ipilimumab together with chemotherapy in the treatment of advanced NSCLC is under research. ${ }^{[71]}$

\section{Nonspecific vaccine approaches}

The most advanced nonspecific vaccine approach for NSCLC is the combination of systemic chemotherapy prepared with dead "Mycobacterium vaccae (SRL172)". The tumor antigens released by chemotherapy are intended to be recognized by the nonspecific immune system. Phase II trials with 20 untreated KHADK patients showed promising results, initiating phase III trials. This trial did not yield higher survival rate compared to combination chemotherapy py (mitomycin- $\mathrm{C}$, vinblastine and 
cisplatin or carboplatin). In adenocarcinoma patients who received two additional SRL172 injections, however, the survival rates of those receiving the vaccine and chemotherapy together increased significantly compared to the previous analysis.

\section{Autologous tumor cells that produce GM-CSF (GVAX)}

In many preclinical models, antitumor immunity is enhanced by the genetic modification of autologous tumor cells with the release of immune regulatory cytokines. Of these cytokines, granulocyte-macrophage colony stimulating factor (GM-CSF) is effective in antitumor immunity. The initial results of two early phase clinical trials of NSCLC patients using GM-CSF-producing autologous tumor cells (GVAX) were promising. Rüttinger et al. ${ }^{[72]}$ reported the protectiveness of this application with local injections in 33 advanced NSCLC patients. In a phase I/II trial with NSCLC patients using GVAX in the early stage $(n=10)$ and advanced stage $(n=33)$, autologous tumor cells were transferred via an adenoviral vector (New Strategies in Advanced Cancer Immunotherapy $172 \mathrm{GM}$ ) and administered as a vaccine. In this trial, $78 \%$ of patients developed antibody reactivation against allogeneic NSCLC cell lines and three responses were obtained. Interestingly, two of these responses were observed in patients with bronchoalveolar carcinoma. Further analysis has shown a correlation between the amount of GM-CSF produced after vaccination and survival rate.

\section{NSCLC dendritic cell vaccines}

In this vaccine administration, dendritic cells (DC) are confronted with various antigens such as antigen presenting cells and administered subcutaneously or intradermally. In a phase I/II clinical trial, 16 patients in stages IB and IIIB were initially treated with surgery, chemoradiation, or various methods and then examined. Six of these 16 patients showed antigen-specific response following vaccination, but clinical results did not show correlation with induced immune response. In another DC-based vaccination application, subcutaneous/intradermal injections of ex vivo-generated dendritic cells modified with recombinant fowlpox vector encoding the carcinoembryonic antigen (CEA) and triple costimulatory molecules "(rF-CEA [6D] -TRICOM) were used. Very few lung cancer patients have been treated with this vaccine, but effective antiCEA immune responses have been observed. Other studies on DC-based vaccines in NSCLC are ongoing. ${ }^{[70]}$

\section{Types of surgery in NSCLC}

Surgery to remove cancer (usually in combination with other treatments) may be an option for early stage NSCLC. It provides the best chance to treat NSCLC if surgery is possible. Lung cancer surgery is a complex operation with serious consequences, and must be performed by a surgeon experienced with lung cancer.

If the surgeon believes the lung cancer can be treated surgically, he will perform pulmonary function tests in advance to assess whether the patient will have sufficient healthy lung tissue after surgery. Other tests are performed to evaluate function of the heart and other organs to ensure that the patient is healthy enough for surgery.

As surgery does not benefit advanced stage lung cancers, the surgeon must assess whether or not the cancer has spread to lymph nodes.

\section{Types of lung surgery}

Various procedures can be performed to treat (and likely cure) NSCLC:

- Pneumonectomy: This surgery removes the entire lung. This may be necessary if the tumor is close to the center of the chest.

- Lobectomy: Lungs comprise of five lobes (three right and two left). In this operation, the entire lobe that contains the tumor is removed. This procedure is generally the most preferred for NSCLC, when possible.

- Segmentectomy (wedge resection): Only one portion of the lobe is removed. This approach is used when the patient does not have enough lung function to tolerate removal of an entire lobe.

- Sleeve resection: Sleeve resection is a bronchoplastic resection method based on the removal pathological bronchial tissue and anastomosis of the ends of healthy bronchus. 
In any of these procedures, nearby lymph nodes are also removed to investigate the possibility of cancer spread. These operations require general anesthesia and are usually performed with a surgical incision between the ribs on the side of the chest (thoracotomy).

The type of surgery the surgeon recommends depends on the size and location of the tumor and how well the lungs function. Doctors often prefer to perform a more extensive surgery (i.e. lobectomy instead of segmentectomy), to provide a better chance of curing cancer if the lungs are healthy enough.

When the patient awakens after surgery, a tube (or tubes) are found attached to a special canister to discharge excess fluid and air from the chest. Tube(s) are used for fluid drainage and air leakage. Patients usually require 5-7 days in the hospital after surgery.

\section{Video assisted thoracic surgery (VATS)}

Currently, early lung cancers in the outer lungs are increasingly treated with a procedure called VATS, which requires smaller incisions than thoracotomy.

During this procedure, a thin, rigid tube with a small video camera at the end is inserted through a small cutter at the edge of the chest to help the surgeon see the inside of the chest on a TV monitor. One or two small incisions are made on the skin and long instruments are passed through these incisions to perform the same procedure using an open approach (thoracotomy). If a lobectomy or pneumonectomy is performed to remove the sample, one of the incisions is enlarged. Since only small incisions are required, there is usually less pain after surgery and a shorter hospital stay (typically 4-5 days).

Most specialist recommend that only earlystage tumors near the outside of the lung be treated with this method. This postoperative cure rate seems to be the same as surgeries performed with larger incisions. However, it is vital that the surgeon performing this procedure is experienced as it requires extensive technical skill.

\section{Potential risks and side effects of lung surgery}

Lung cancer surgery is a major operation and may have serious side effects, therefore, it is not for everyone. While all operations carry risks, to a degree, it depends on the scope of the operation and the patient's health.

Potential complications during and immediately after surgery include: anesthesia reactions, excessive bleeding, blood clots in the legs or lungs, wound infections, and pneumonia. Although rare, some people may die in surgery.

Recovery after lung cancer surgery typically takes weeks or months. If the operation is performed with a thoracotomy (a long incision in the chest), the surgeon has to spread the ribs to reach the lungs, so the area near the incision will be damaged for some time after the operation. People who undergo VATS instead of thoracotomy experience less pain and heal faster.

If the patient's lungs are in good condition (aside from the presence of cancer), it can usually return to normal activities after a period of time, if a lobe or even an entire lung is removed. In addition, patients with additional lung disease, such as emphysema or chronic bronchitis (common among long-term smokers), may experience shortness of breath at certain activity levels after surgery.

\section{Lung cancer surgery with limited spread to other organs}

In case the lung cancer has spread to the brain or adrenal gland and there is only a single tumor, the patient may benefit from tumor removal. This operation should be considered only if the tumor in the lung can be completely removed. Even then, not all lung cancer specialists accept this approach, especially if the tumor is in the adrenal gland.

For tumors in the brain, this treatment is performed surgically (called craniotomy) through a hole in the skull. It should only be done if the tumor can be removed without damaging the vital regions of the brain. ${ }^{.73]}$

Positive margins (border) following pulmonary resection of NSCLC occur in about 5-15\% of patients who undergo a curative procedure. The presence of positive margins adversely affects long-term outcomes due to local and potentially distant disease recurrence. ${ }^{[74]}$ 


\section{NOVEL DRUGS IN TREATMENT}

Treatment options for lung cancer patients are rapidly developing. In the last two years, more treatments have been approved by the US Food and Drug Administration (FDA) for the treatment of lung cancer than have been approved in the previous decade. New life-saving therapies are being rapidly advancing with clinical research.

Sequential treatment with afatinib (Gilotrif) and osimertinib (Tagrisso) showed a long-term overall survival (OS) of up to four years in patients with NSCLC with EGFR deletion 19 (del19)-positive tumors. ${ }^{[75]}$

FDA approved pembrolizumab (Keytruda) is an immunotherapy treatment that can be used in the first-line treatment of patients with stage III NSCLC. ${ }^{\text {76] }}$

Activation of the MET pathway via MET mutation or amplification is an important oncogenic mechanism in NSCLC. MET exon 14 skip mutations and high elevations of MET are associated with poor prognosis in NSCLC patients, and the availability of new treatment options is an unmet need for these patients. Capmatinib is a specific and potent small molecule MET inhibitor with antitumor activity in NSCLC both in vivo and in vitro. Combinations of Capmatinib with third generation EGFR-TKIs are actively being researched. The use of capmatinib in combination with other kinase inhibitors as in in vitro may be a significant therapeutic option in the future. Overall, capmatinib is a promising new treatment option for patients with NSCLC regulated by MET. ${ }^{[77]}$

Despite the increasing importance of immune checkpoint inhibitors, chemotherapy is still a mainstay in the approach to NSCLC. Among different chemotherapies, microtubule targeting agents (MTAs), alone or in combination, represent the standard of care in different environments. Research on tubulin inhibitors belonging to a new generation of MTA have shown encouraging results related to clinical activity, especially in phase I and II trials. ${ }^{[7]}$

Melatonin is an appropriate complementary therapy that should be considered to increase clinical benefits and improve poor outcomes in NSCLC treatment. Melatonin acts by affecting gene expression, apoptotic pathways, and proliferation of tumor cells. ${ }^{\text {78] }}$
Necitumumab is a humanized IgG1 anti-EGFR. In the Phase III SQUIRE study, necitumumab used as a first-line treatment with cisplatin and gemcitabine showed a reduced risk of cancerrelated mortality and a better disease control rate in advanced squamous NSCLC. Therefore, necitumumab is now a novel first-line treatment option for squamous NSCLC. ${ }^{\text {[79] }}$

\section{Declaration of conflicting interests}

The authors declared no conflicts of interest with respect to the authorship and/or publication of this article.

\section{Funding}

The authors received no financial support for the research and/or authorship of this article.

\section{REFERENCES}

1. Travis WD, Brambilla E, Müller-Hemerlink HK, Harris CC. Pathology and genetics of tumors of the lung, pleura, thymus and heart. In: World Health Organization classification of tumors. Lyon: IARC Press; 2004. p. 9-144.

2. Wahbah M, Boroumand N, Castro C, El-Zeky F, Eltorky M. Changing trends in the distribution of the histologic types of lung cancer: a review of 4,439 cases. Ann Diagn Pathol 2007;11:89-96.

3. Michèle N. De Waele, Paul E. Van Schil Department of Thoracic and Vascular Surgery, Antwerp University Hospital, Wilrijkstraat 10, B-2650 Edegem (Antwerp), Belgium

4. Balta BZ, Üre ÖS, Erturan S, Aydın G. İleri evre küçük hücreli dışı akciğer kanserinde prognostik faktörler. Med Bull Haseki 2013; 51: 57-60.

5. Duma N, Santana-Davila R, Molina JR. Non-small cell lung cancer: epidemiology, screening, diagnosis, and treatment. Mayo Clin Proc 2019;94:1623-40.

6. Hayretdağ HA, Akkoçlu A. Akciğer kanseri epidemiyolojisi. Türkiye Klinikleri J Surg Med Sci 2006;2:58-65.

7. Didkowska J, Wojciechowska U, Manczuk M, Lobaszewski J. Lung cancer epidemiology: contemporary and future challenges worldwide. Ann Transl Med 2016;4:150.

8. Akciğer ve Plevra maligniteleri çalışma grubu. Akciğer kanseri tanı ve tedavi rehberi. Toraks Dergisi 2006;7(Ek 2):1-37.

9. Alberg AJ, Samet JM. Epidemiology of lung cancer. Chest 2003;123:21S-49S.

10. Rivera MP, Stover DE. Gender and lung cancer. Clin Chest Med 2004;25:391-400.

11. Dela Cruz CS, Tanoue LT, Matthay RA. Lung cancer: epidemiology, etiology, and prevention. Clin Chest Med 2011;32:605-44.

12. Aldington S, Harwood M, Cox B, Weatherall M, Beckert L, Hansell A, et al. Cannabis use and risk 
of lung cancer: a case-control study. Eur Respir J 2008;31:280-6.

13. Cicek Y, Kosar PA, Öztürk Ö. Molecular genetics of lung cancer. Eurasian J Pulmonol 2018;20:111-7.

14. Karabulut Gül Ş. Lokal ileri küçük hücreli dışı akciğer kanserinde protein kinaz B/AKT ileti yolunun prognozla ilişkisi. [Uzmanlık Tezi], İstanbul: Dr. Lütfi Kırdar Kartal Eğitim ve Araştırma Hastanesi Radyasyon Onkolojisi Kliniği; 2009.

15. Koudelakova V, Kneblova M, Trojanec R, Drabek $J$, Hajduch M. Non-small cell lung cancer--genetic predictors. Biomed Pap Med Fac Univ Palacky Olomouc Czech Repub 2013;157:125-36.

16. Chiba I, Takahashi T, Nau MM, D'Amico D, Curiel DT, Mitsudomi T, et al. Mutations in the p53 gene are frequent in primary, resected non-small cell lung cancer. Lung Cancer Study Group. Oncogene 1990;5:1603-10.

17. Zhang JG, Wang JJ, Zhao F, Liu Q, Jiang $\mathrm{K}$, Yang GH. MicroRNA-21 (miR-21) represses tumor suppressor PTEN and promotes growth and invasion in non-small cell lung cancer (NSCLC). Clin Chim Acta 2010;411:846-52.

18. Pauwels P. Akciğer kanserinde klinik öneme sahip mutasyonlar. Available at: https://www.toraks.org.tr/ uploadFiles/book/file/6112012162228-173176.pdf

19. Anderson MLM, Spandidos DA. Oncogenes and onco-suppressor genes in lung cancer. Respiratory Medicine 1993;87:413-20.

20. Siegel R, Ward E, Brawley O, Jemal A. Cancer statistics, 2011: the impact of eliminating socioeconomic and racial disparities on premature cancer deaths. CA Cancer J Clin 2011;61:212-36.

21. Minna J, Schiller J. Harrison's principles of internal medicine. 17th ed. New York: McGraw-Hill; 2008.

22. Wingo PA, Ries LA, Giovino GA, Miller DS, Rosenberg HM, Shopland DR, et al. Annual report to the nation on the status of cancer, 1973-1996, with a special section on lung cancer and tobacco smoking. J Natl Cancer Inst 1999;91:675-90.

23. European Gender Medicine (EUGENMED) Sex and Gender in Lung Cancer; 2015. Available at: https://eurohealth.ie/wp-content/uploads/2016/09/ EUGenMed_LC.pdf

24. Menck HR, Henderson BE. Cancer incidence patterns in the Pacific Basin. Natl Cancer Inst Monogr 1982;62:101-9.

25. Centers for Disease Control and Prevention (CDC). Vital signs: current cigarette smoking among adults aged >or=18 years --- United States, 2009. MMWR Morb Mortal Wkly Rep 2010;59:1135-40.

26. Howlader N, Noone AM, Krapcho M, editors. SEER Cancer Statistics Review, 1975-2008. Bethesda: National Cancer Institute; 2010.

27. Wingo PA, Cardinez CJ, Landis SH, Greenlee RT, Ries LA, Anderson RN, et al. Long-term trends in cancer mortality in the United States, 1930-1998. Cancer 2003;97:3133-275.
28. Blanchard EM, Arnaoutakis K, Hesketh PJ. Lung cancer in octogenarians. J Thorac Oncol 2010;5:909-16.

29. Gridelli C1, Langer C, Maione P, Rossi A, Schild SE. Lung cancer in the elderly. J Clin Oncol 2007;25:1898-907.

30. Mornex JF, Thivolet F, De las Heras M, Leroux C. Pathology of human bronchioloalveolar carcinoma and its relationship to the ovine disease. Curr Top Microbiol Immunol 2003;275:225-48.

31. Castro CY, Ostrowski ML, Barrios R, Green LK, Popper HH, Powell S, et al. Relationship between Epstein-Barr virus and lymphoepithelioma-like carcinoma of the lung: a clinicopathologic study of 6 cases and review of the literature. Hum Pathol 2001;32:863-72.

32. Bando M, Takahashi M, Ohno S, Hosono T, Hironaka $\mathrm{M}$, Okamoto $\mathrm{H}$, et al. Torque teno virus DNA titre elevated in idiopathic pulmonary fibrosis with primary lung cancer. Respirology 2008;13:263-9.

33. Travis WD, Brambilla E, Burke AP, Marx A, Nicholson AG. Introduction to The 2015 World Health Organization Classification of Tumors of the Lung, Pleura, Thymus, and Heart. J Thorac Oncol 2015;10:1240-2.

34. Ergelen R, Çimşit ÇN. Akciğer tümörleri. Toraks Cerrahi Bülteni 2013;4:178-88.

35. Rosado-de-Christenson ML, Templeton PA, Moran CA. Bronchogenic carcinoma: radiologic-pathologic correlation. Radiographics 1994;14:429-46.

36. Siegel RL, Miller KD, Jemal A. Cancer statistics, 2018. CA Cancer J Clin 2018;68:7-30.

37. Kocher F, Hilbe W, Seeber A, Pircher A, Schmid T, Greil R, et al. Longitudinal analysis of 2293 NSCLC patients: a comprehensive study from the TYROL registry. Lung Cancer 2015;87:193-200.

38. Akciğer ve Plevra Maligniteleri Çalışma Grubu. Akciğer kanseri tanı ve tedavi rehberi. Toraks Dergisi 2006;7(Ek 2):1-35.

39. Beckles MA, Spiro SG, Colice GL, Rudd RM. Initial evaluation of the patient with lung cancer: symptoms, signs, laboratory tests, and paraneoplastic syndromes. Chest 2003;123:97S-104S.

40. Collins LG, Haines C, Perkel R, Enck RE. Lung cancer: diagnosis and management. Am Fam Physician 2007;75:56-63.

41. Damadoğlu E. Küçük hücreli dışı akciğer kanserinde tanı ve tedavi gecikmeleri ve bu gecikmelerin patolojik tümör evresine etkisi. [Uzmanlık Tezi], İstanbul: Süreyyapaşa Göğüs Hastalıkları ve Göğüs Cerrahisi Eğitim ve Araştırma Hastanesi; 2007.

42. McLoud TC. Imaging techniques for diagnosis and staging of lung cancer. Clin Chest Med 2002;23:123-36.

43. Dwamena BA, Sonnad SS, Angobaldo JO, Wahl RL. Metastases from non-small cell lung cancer: mediastinal staging in the 1990s--meta-analytic comparison of PET and CT. Radiology 1999;213:530-6. 
44. Pretreatment evaluation of non-small-cell lung cancer. The American Thoracic Society and The European Respiratory Society. Am J Respir Crit Care Med 1997;156:320-32.

45. Kumanlıoğlu K, Değirmenci B. Akciğer kanserlerinde nükleer tıbbın yeri. In: Haydaroğlu A, editör. Akciğer kanserleri: Tanı ve tedavi. İzmir: Ege Üniversitesi Basımevi; 2000. s. 139-46.

46. Ferrigno D, Buccheri G, Biggi A. Serum tumour markers in lung cancer: history, biology and clinical applications. Eur Respir J 1994;7:186-97.

47. British Thoracic Society Bronchoscopy Guidelines Committee, a Subcommittee of Standards of Care Committee of British Thoracic Society. British Thoracic Society guidelines on diagnostic flexible bronchoscopy. Thorax. 2001;56:i1-21.

48. Hirose T, Mori K, Machida S, Tominaga K, Yokoi K, Adachi M. Computed tomographic fluoroscopy-guided transthoracic needle biopsy for diagnosis of pulmonary nodules. Jpn J Clin Oncol 2000;30:259-62.

49. Dahlstrom JE, Langdale-Smith GM, James DT. Fine needle aspiration cytology of pulmonary lesions: a reliable diagnostic test. Pathology 2001;33:13-6.

50. Masters GA, Temin S, Azzoli CG, Giaccone G, Baker S Jr, Brahmer JR, et al. Systemic Therapy for Stage IV Non-Small-Cell Lung Cancer: American Society of Clinical Oncology Clinical Practice Guideline Update. J Clin Oncol 2015;33:3488-515.

51. Kaya A, Güngör A, Gönüllü U. İnvaziv tanı yöntemleri. In: Akkoçlu A, Öztürk C, editörler. Toraks Kitapları. Akciğer kanseri; multidisipliner yaklaşım. Ankara: Bilimsel Tip Yayınevi; 1999. s. 38-43.

52. Yılmaz A, Akkaya E, Baran R. Transtorasik iğne aspirasyonu. Tüberküloz ve Toraks 2002;50:295300.

53. Gönüllü U. Bronş kanserleri. In: Numanoğlu N, editör. Solunum sistemi ve hastalıkları. Ankara: Antıp; 1997. s. 593-631.

54. Nicholson AG, Chansky K, Crowley J, Beyruti $\mathrm{R}$, Kubota K, Turrisi A, et al. The International Association for the Study of Lung Cancer Lung Cancer Staging Project: Proposals for the Revision of the Clinical and Pathologic Staging of Small Cell Lung Cancer in the Forthcoming Eighth Edition of the TNM Classification for Lung Cancer. J Thorac Oncol 2016;11:300-11.

55. Rami-Porta R, Bolejack V, Crowley J, Ball D, Kim J, Lyons G, et al. The IASLC Lung Cancer Staging Project: Proposals for the Revisions of the T Descriptors in the Forthcoming Eighth Edition of the TNM Classification for Lung Cancer. J Thorac Oncol 2015;10:990-1003.

56. Detterbeck FC. The eighth edition TNM stage classification for lung cancer: What does it mean on main street?. J Thorac Cardiovasc Surg 2018;155:3569.
57. Asamura H, Chansky K, Crowley J, Goldstraw P, Rusch VW, Vansteenkiste JF, et al. The International Association for the Study of Lung Cancer Lung Cancer Staging Project: Proposals for the Revision of the N Descriptors in the Forthcoming 8th Edition of the TNM Classification for Lung Cancer. J Thorac Oncol 2015;10:1675-84.

58. De Leyn P, Lardinois D, Van Schil PE, Rami-Porta R, Passlick B, Zielinski M, et al. ESTS guidelines for preoperative lymph node staging for non-small cell lung cancer. Eur J Cardiothorac Surg 2007;32:1-8.

59. Howington JA, Blum MG, Chang AC, Balekian AA, Murthy SC. Treatment of stage I and II non-small cell lung cancer: Diagnosis and management of lung cancer, 3rd ed: American College of Chest Physicians evidence-based clinical practice guidelines. Chest 2013;143:e278S-e313S.

60. Gridelli C, Ardizzoni A, Le Chevalier T, Manegold $\mathrm{C}$, Perrone $\mathrm{F}$, Thatcher $\mathrm{N}$, et al. Treatment of advanced non-small-cell lung cancer patients with ECOG performance status 2: results of an European Experts Panel. Ann Oncol 2004;15:419-26.

61. Zappa C, Mousa SA. Non-small cell lung cancer: current treatment and future advances. Transl Lung Cancer Res 2016;5:288-300.

62. Chemotherapy in non-small cell lung cancer: a meta-analysis using updated data on individual patients from 52 randomised clinical trials. Nonsmall Cell Lung Cancer Collaborative Group. BMJ 1995;311:899-909.

63. Amini A, Yeh N, Gaspar LE, Kavanagh B, Karam SD. Stereotactic body radiation therapy (SBRT) for lung cancer patients previously treated with conventional radiotherapy: a review. Radiat Oncol 2014;9:210.

64. NCCN Clinical Practice Guidelines in Oncology (NCCN Guidelines ${ }^{\circledR}$ ) Non-Small Cell Lung Cancer Version 2. 2020-December 23, 2019.

65. Videtic GMM, Donington J, Giuliani M, Heinzerling J, Karas TZ, Kelsey CR, et al. Stereotactic body radiation therapy for early-stage non-small cell lung cancer: executive summary of an ASTRO evidencebased guideline. Pract Radiat Oncol 2017;7:295-301.

66. Aupérin A, Le Péchoux C, Rolland E, Curran WJ, Furuse K, Fournel $\mathrm{P}$, et al. Meta-analysis of concomitant versus sequential radiochemotherapy in locally advanced non-small-cell lung cancer. J Clin Oncol 2010;28:2181-90.

67. Kunitoh H, Kato H, Tsuboi M, Shibata T, Asamura $\mathrm{H}$, Ichinose $\mathrm{Y}$, et al. Phase II trial of preoperative chemoradiotherapy followed by surgical resection in patients with superior sulcus non-small-cell lung cancers: report of Japan Clinical Oncology Group trial 9806. J Clin Oncol 2008;26:644-49.

68. Suntharalingam M, Paulus R, Edelman MJ, Krasna M, Burrows W, Gore E, et al. Radiation therapy oncology group protocol 02-29: a phase II trial of neoadjuvant therapy with concurrent chemotherapy and full-dose radiation therapy followed by surgical resection and 
consolidative therapy for locally advanced non-small cell carcinoma of the lung. Int $\mathrm{J}$ Radiat Oncol Biol Phys 2012;84:456-63.

69. Ashworth AB, Senan S, Palma DA, Riquet M, Ahn YC, Ricardi U, et al. An individual patient data metaanalysis of outcomes and prognostic factors after treatment of oligometastatic non-small-cell lung cancer. Clin Lung Cancer 2014;15:346-55.

70. Aydınoğlu Işıtmangil G. Akciğer kanser immünoterapisinde yeni stratejiler. Haydarpaşa Numune Eğitim ve Araştırma Hastanesi Tıp Dergisi 2013;53:168-77.

71. Doherty C. Immunotherapies for Non-Small Cell Lung Cancer. Avaliable at: https://www.verywellhealth. com/immunotherapies-for-non-small-cell-lungcancer-4145301 [Accessed: March 14, 2019]

72. Rüttinger D, HatzR, Jauch KW, Fox BA. Novel strategies for lung cancer immunotherapy. In: Shields TW, LoCicero J, Reed CE, Feins RH, editors. General Thoracic Surgery. 7th ed. Philadelphia: Lippincott Williams \& Wilkins; 2009. p. 1529-38.

73. Treating Non-Small Cell Lung Cancer. Avaliable at: https://www.cancer.org/cancer/lung-cancer/treating- non-small-cell.html

74. Predina JD, Keating J, Patel N, Nims S, Singhal S. Clinical implications of positive margins following non-small cell lung cancer surgery. J Surg Oncol 2016;113:264-9.

75. Long-Term Survival for EGFR+NSCLC. Lung Cancer Foundation of America; 2019. Avaliable at: https:// lcfamerica.org/research-grants/latest/research/longterm-survival-for-egfr/

76. Treatment advances. Lung Cancer Research Foundation. https://www.lungcancerresearch foundation.org/treatment-advances/

77. Vansteenkiste JF, Van De Kerkhove C, Wauters E, Van Mol P. Capmatinib for the treatment of nonsmall cell lung cancer. Expert Rev Anticancer Ther 2019;19:659-71.

78. Pourhanifeh MH, Sharifi M, Reiter RJ, Davoodabadi A, Asemi Z. Melatonin and non-small cell lung cancer: new insights into signaling pathways. Cancer Cell Int 2019;19:131.

79. Díaz-Serrano A, Sánchez-Torre A, Paz-Ares L. Necitumumab for the treatment of advanced nonsmall-cell lung cancer. Future Oncol 2019;15:705-16. 